\title{
Guerras profanas
}

\author{
Seyla Benhabib
}

Yale University

\section{Resumen}

Según la autora de este trabajo, los actos siniestros perpetrados por cuerpos convertidos en arma no están vinculados con ningún contenido religioso según el cual, por decirlo de este modo, una liberación de la prisión del cuerpo impuro, o de la comunidad religiosa frente al menosprecio de Otro, conlleven una autoaniquilación con la exigencia simultánea de aniquilar a miles de civiles. Como Benhabib mencionó en otra parte con relación a la hermenéutica, la comprensión religiosa no tiene por qué dejar de implicar «comprensión que es también interpretación y una "fusión de horizontes", un diálogo a través del tiempo, las generaciones y perspectivas" y esto nos lleva a concluir que las orientaciones valorativas (de corte religioso) de la acción no se pueden encerrar en sí mismas sin proceder a la autocrítica de sus propios fundamentos. Para Benhabib, el problema no es tanto creer en algo, sino cómo creemos en algo. Los fundamentalistas que destruyen las Torres Gemelas tienen objetivos muy profanos, como cualquier otro actor político, enmascarados de retórica religiosa. Son nihilistas en los fines, pero radicales fundamentalistas en los medios.

Palabras clave: modernidad, guerra profana, choque de civilizaciones, fundamentalismo.

\section{Abstract. Profane Wars}

According to the author of this paper, the sinister acts perpetrated by bodies transformed in weapons are not linked with any religious meaning according to which the liberation from the polluted body prison or from the religious community facing the undervaluation or disrespect of the other could drive towards a self-killing and the mass killing of innocent civilians. The fundamentalist who destroyed the Twin Towers have very unholy goals, as any other political actor struggling in the political arena, masked and hide behind the religious rhetoric. They are nihilistic subjects considering the ends they pursue but fundamentalist radicals considering the media they use to fulfil such ends.

Key words: modernity, unholy war, clash of civilizations, fundamentalism.

\section{I}

Desde el once de septiembre de 2001 ha quedado claro que nos enfrentamos a una nueva forma de lucha que amenaza con disolver las fronteras de aquello que es político en las democracias liberales. La red de terror de Osama bin Laden, y sus diversas ramas en Egipto, Pakistán, Malasia, Indonesia, Filipinas, Argelia, y entre grupos islamistas de Europa occidental, es más ancha, más 
atrincherada y más sofisticada de lo que se creía. Los ataques desatados por estos grupos (y sus simpatizantes potenciales en los Estados Unidos y en Europa, entre los neonazis y los defensores de la supremacía blanca), especialmente el uso del arma biológica ántrax para contaminar a la población civil por la vía del correo, indican un nuevo fenómeno político y militar que desafía el marco de la política centrada en el estado.

Los historiadores siempre nos avisan que aquello que no tiene precedentes, acaba teniendo precursores en algún lugar, y que aquello que hoy parece nuevo, parecerá viejo cuando lo consideremos con el trasfondo de un espacio de tiempo más largo. Sin embargo, "pensar lo que es nuevo» en política es la vocación del intelectual. Ésta es una tarea en la que Susan Sontag, Fred Jameson y Slavoj Zizek nos han fallado al interpretar estos acontecimientos junto con el cansado paradigma de la lucha antiimperialista por parte de los «desheredados de la Tierra» ${ }^{\perp}$. Olvidando la dinámica interna y las luchas dentro del mundo islámico y la historia de conflictos regionales en Afganistán, Pakistán, India y Cachemira, estos análisis nos aseguran que podemos continuar entendiendo el mundo con nuestras categorías usuales, y que cuando culpamos a las políticas y a las acciones de los gobiernos occidentales nos podemos purgar de la enemistad y el odio que se dirige hacia nosotros como miembros de estas sociedades occidentales. Estos análisis no nos ayudan a entender la naturaleza sin precedentes de los acontecimientos que han tenido lugar desde el 11 de septiembre de 2001, ni a apreciar las dinámicas internas del mundo árabe musulmán que los provocaron.

La línea entre objetivos militares y civiles, entre ejército y poblaciones civiles, ya se había borrado con los bombardeos aéreos de la Segunda Guerra Mundial. Esto no es lo nuevo desde el 11 de septiembre. Enfrentadas a la movilización total de la sociedad, que empezó con el fascismo y el nacionalsocialismo, fueron las democracias del mundo, y no un grupo terrorista marginal escondido en las montañas de Afganistán, las que primero traspasaron aquella línea e iniciaron la «guerra total». La población civil en general pasó a ser rehén del enemigo, igual que durante los bombardeos sobre Londres por parte de los nazis, y los de Dresde, Hiroshima y Nagasaki por parte de los aliados, más tarde.

En la década de los cincuenta, la guerra de Argelia marcó una nueva variación en el proceso de borrado de la línea entre el frente y el hogar, el soldado y el civil. La Resistencia argelina contra los franceses pretendía destruir la normalidad de la vida cotidiana de los civiles de la población ocupante. Con las explosiones en los cafés, mercados y estaciones, la Resistencia no tan sólo recordaba a los residentes franceses de Argelia que eran el enemigo, sino también que no podría haber «vida normal» bajo las condiciones de la ocupación colonial. Desde entonces, este tipo de terror — que lucha contra las armas milita-

1. Ver Susan SonTag, The New Yorker, 24 de septiembre de 2001; Fred Jameson, The London Review of Books, 23, núm. 19, 4 de octubre de 2001, y Slavoj ZizeK, "The Desert of the Real: Is this the End of Fantasy?», In These Times, 20 de octubre de 2001. 
res y técnicas superiores de un enemigo más poderoso, haciendo de cada autobús o estación de tren, de cada esquina o lugar de reunión, un objetivo potencial- se ha convertido en una de las «armas preferidas de los débiles». La estrategia de este tipo de lucha es hacer la vida tan invivible para los civiles del enemigo que se den por vencidos pese a que disfruten de superioridad militar. La Intifada Palestina, al menos en parte, sigue el modelo argelino: al crear condiciones de continuo miedo, inseguridad y violencia a la tierra de Palestina, pretende destruir el propósito de la población civil israelí de continuar con la vida normal ${ }^{2}$. En estos últimos años, no obstante, los infiltrados de grupos islamistas, como por ejemplo Hamas y Hizbollah, en las filas de los palestinos, y la práctica extendida de los «terroristas suicidas» están cambiando también la naturaleza de la Intifada.

El bombardeo del World Trade Center y el Pentágono es distinto, tanto de la guerra total en la lucha contra el fascismo, como del terrorismo contra el ocupante iniciado por los argelinos. Estos nuevos ataques, perpetrados contra una población civil en su propia tierra y contra un país que no se encontraba en hostilidad declarada con los atacantes, no sólo desafían a todas las categorías de la ley internacional, sino que también reducen la política a símbolos apocalípticos. Hasta que Osama bin Laden no emitió su conciso vídeo que celebraba el once de septiembre, su gesta no tenía nombre político: ¿En nombre de quién o para quién actúa este grupo? ¿Qué exigencias políticas plantea? Las breves referencias a las tropas americanas estacionadas en Arabia Saudí, a las sanciones de los Estados Unidos en Irak y al apoyo de los Estados Unidos a Israel estaban rodeadas del lenguaje de la jihad ('guerra santa') y ofuscadas por alusiones a la gloria perdida del islam en el siglo XIII con la pérdida de al-Andalus (España), que pasó a manos de los cristianos. Aunque es concebible que el terror palestino pueda acabar cuando Israel se retire de la ocupada Franja de Gaza, libere los prisioneros de guerra palestinos, encuentre un asentamiento para los refugiados y resuelva, de alguna manera, la cuestión de Jerusalén, no está claro que pueda acabar con la jih ad de la red de Osama bin Laden en los Estados Unidos y sus aliados. La suya es una guerra de revancha «santa», una guerra destinada a humillar el poderoso «Satán» en Nueva York y en Washington, volviendo las armas de la tecnología más desarrollada en contra de la sociedad que las ha creado.

El resultado es una combinación sublime de hechicería y atavismo moral y político, denominado por algunos «jihad online». Pero esta política impía ame-

2. La analogía no es del todo exacta, porque los colonizadores franceses abandonaron finalmente de Argelia. Pese a todas las teorías contrarias, la población judía de Palestina no es colonizadora en el sentido tradicional del término. No está allí para explotar a la población indígena o a sus recursos, sino para establecer una "patria judía» — por más que esta visión sea problemática y trágica. La negativa de la mayor parte del mundo árabe a comprender como es de único el sueño que motivó a la iniciativa judía, lo facilita la comparación de Israel con el modelo del opresor occidental mientras se presentan a sí mismos como colonizados y oprimidos. Israel no se estableció por ser una fuerza colonizadora; ello ha ido aconteciendo desde la ocupación de la Franja de Gaza y desde su dependencia creciente de la mano de obra palestina para gestionar su economía en expansión. 
naza con deshacer las distinciones morales y políticas que tendrán que gobernar nuestras vidas, distinciones entre enemigo, amigo y espectador; culpa, complicidad y responsabilidad; conflicto, combate y guerra. Tenemos que vivir de acuerdo con ellas, pese a que otros no lo hagan.

Uno de los argumentos escuchados más frecuentemente después del once de septiembre era que, aunque los ataques terroristas del World Trade Center y de Washington equivalían a una guerra respecto a los daños sobre los civiles y contra la propiedad, a la intencionalidad y precisión con que fueron ejecutados, y al cinismo con que violaron las normas morales, legales e internacionales, el Congreso de los Estados Unidos no podía, de hecho, declarar la "guerra", no porque el enemigo aún fuera desconocido, sino porque un estado sólo puede declarar la guerra a otro estado. La idea de que un estado nacional democrático declarara la guerra contra una red global, más o menos organizada, de simpatizantes de una causa religiosa y de civilización, forzó todas las categorías de la ley internacional con la que el mundo había vivido desde 1945, y donde los estados nacionales eran reconocidos como actores principales. Es por esta razón que la actual acción militar en Afganistán no ha ido precedida de una declaración de guerra; al contrario, el Congreso ha autorizado al presidente a hacer todo aquello que sea necesario para luchar contra la red de terror global y llevar ante la justicia a los perpetradores, pero no ha declarado la guerra ni contra los talibanes (a quien la mayoría de los países no reconoce como régimen legítimo) ni contra el pueblo afgano. Es como si el territorio, el terreno de Afganistán, fuera nuestro enemigo, en la medida que este terreno ofrece refugio y una base de operaciones a uno de los más grandes fugitivos de nuestro tiempos, Osama bin Laden. Irónicamente, el pueblo de Afganistán ha caído él mismo "cautivo» o "prisionero» de alguien que opera en su territorio a quien los talibanes han dado refugio. Afganistán es un estado nacional en decadencia o fracasado, y esta misma situación de decadencia nos permite comprender aún más intensamente los principios de soberanía nacional que han gobernado las relaciones internacionales desde la Segunda Guerra Mundial.

Recordamos aquí la definición modernista clásica que Max Weber hace del estado como «el monopolio legítimo del uso de la violencia dentro de un territorio reconocido y limitado" ${ }^{3}$. La estatalidad moderna se basa en la combinación de los principios de territorialidad de monopolio administrativo y militar, incluyendo el uso de la violencia y la legitimidad para hacerlo. Cuando los estados están en decadencia, se disuelven o se escinden, estos tres principios se desmenuzan. Su territorio se puede convertir en terreno para la puesta en escena de operaciones no solamente de guerra de guerrillas, sino también de contra-

3. «Sin embargo, la monopolización de la violencia legítima por parte de la asociación político-territorial y sus consociaciones racionales en un orden institucional no son nada primordiales, sino un producto de la evolución» (Max Weber, Economy and Society, vol. 2., Guenther Roth y Claus Wittich (eds.), Berkeley, University of California Press, 1978, p. 904-905). 
bando de drogas, producción de armas, contrabando en general y otras actividades ilegales; la competencia administrativa y militar está comprendida por unidades en el ámbito subestatal, como por ejemplo señores de la guerra, comandos, jefes de clan o líderes religiosos; y la legitimidad pierde su calidad representativa en la medida que ya no hay un pueblo unificado a la voluntad del cual se refiere o se somete - la legitimidad emana bien del cañón de un arma o bien de otras visiones ideológicas del mundo, supranacionales y subnacionales, ya sean basadas en la raza, la religión o la civilización.

Los decadentes y débiles estados nacionales del mundo contemporáneo tienen similitudes y diferencias con los regímenes totalitarios de mediados del siglo XX. Esta ruptura del imperio de la ley, la destrucción de las instituciones democráticas y representativas, la presencia generalizada de la violencia y la universalización del miedo son características de ambas formas de estado. Aunque a veces movilizaban "al movimiento» contra la burocracia estatal, los regímenes totalitarios de mediados del siglo XX, en general, fortalecieron y reconstruyeron el estado subordinándolo a sus ideologías. Pero los estados postmodernos casi feudales del presente, como por ejemplo Afganistán, Chechenia, Bosnia y Ruanda, surgen como resultado, no del fortalecimiento, sino de la destrucción de la unidad territorial y administrativa del estado en aras de las subunidades, las cuales están, por lo tanto, interconectadas a nivel global. Como nos demuestra Hannah Arendt, los movimientos totalitarios también tenían ambiciones globalizadoras en la medida que pregonaban ideologías supranacionales, como por ejemplo el pangermanismo y el paneslavismo ${ }^{4}$. Aun así, las ideologías globales de los movimientos actuales del terror tienen un alcance a su vez más pequeño y más grande: en lugar de la ideología de unidad lingüística o cultural entre las naciones eslavas o germánicas, por ejemplo, nos encontramos hoy con ideologías destinadas a tribus, etnias o a una visión de una comunidad de creyentes que las trasciende — es decir, la Umma islámica de los creyentes. La nueva unidad de totalitarismo es la célula terrorista, no el partido o el movimiento: El objetivo de esta nueva forma de guerra no es sólo la destrucción del enemigo, sino también la extinción de una forma de vida. La aparición de agentes no estatales capaces de ocasionar destrucción a unos niveles que hasta ahora sólo eran competencia de los estados, y la aparición de una visión ideológica supranacional con un indefinible contenido moral y politico, que dificilmente se puede satisfacer con tácticas politicas y negociaciones ordinarias, son los aspectos sin precedentes de nuestra situación actual.

Con esta observación, no quiero dar a entender que atribuyo una racionalidad o una normatividad general al uso de la violencia por parte del estado. El terrorismo de estado también puede ser brutal, injusto y despiadado - iRecordemos la guerra del estado yugoslavo contra los bosnios y los albanokosovares! - . El punto que quiero subrayar, no obstante, es que, en las

4. Hannah ARENDT, The Origins of Totalitarianism, New York, Harcourt, Brace, Jovanovich, 1979 (1951), p. 3. 
democracias liberales, el monopolio que reclama el estado sobre el uso de medios violentos está siempre, en principio, si no de hecho, sujeto al imperio de la ley y a la legitimación democrática de la ciudadanía. Estas limitaciones internas, con respecto al uso legítimo de la violencia se trasladan al ámbito internacional, donde los estados soberanos se comprometen a limitar su uso mediante pactos y asociaciones, firmando tratados, etc.

El fin del mundo bipolar de la Guerra Fría comportó no tan sólo pluralidad, sino también una sociedad global en la que no ha aparecido ningún actor estatal con medios para ejercer violencia que no esté sujeto a las limitaciones usuales de las leyes y los tratados internacionales. Todos los tratados que hasta ahora han regido la no-utilización y la no-proliferación de armas biológicas, químicas y nucleares se han mostrado irrelevantes: aquéllos que las desplegarán, nunca han firmado los tratados. Es más, al no haber sido reconocidos como entidades políticas legítimas, estos grupos no son responsables ni tienen que dar cuentas ante las poblaciones en medio de las cuales actúan, y que los esconden. Suponemos que Osama bin Laden y su grupo tienen misiles Scud con ojivas nucleares, que pueden haber conseguido de Iraq, de la mafia rusa o de otros contrabandistas. ¿Qué les impediría disparar estos misiles contra los centros de población en Afganistán, Pakistán, India o Israel si esto tuviera alguna utilidad? Como no son responsables ante nadie, los daños colaterales que pueden causar incluso a sus aliados y simpatizantes no les importan en absoluto. Mientras grupos terroristas, como por ejemplo el vasco ETA y el IRA, aún han de guiarse por algún tipo de proporción en el daño que infligen y en la violencia en la que están inmersos con objeto de no perder solidaridad por su causa ante la opinión pública mundial, estas nuevas redes del terror no están motivadas por previsibles objetivos políticos similares a la independencia de la tierra vasca de España y Francia, la eliminación de la población lealista irlandesa y la unificación con la católica Irlanda, y de otras por el estilo. Estos grupos tampoco luchan por los corazones y las mentes de occidente, buscando la conversión de la población al islam y a la forma de vivir islámica. Cuando era practicada por los ejércitos islámicos durante los siglos posteriores a la muerte de Mahoma (623 aC), la jihad — que significa también la lucha del alma consigo misma por llevar una vida virtuosa tal y como lo manda el Corán- 5 estaba dirigida a la conquista de la tierra de los «infieles» para forzar su conversión al islam. La gente de todas las razas, colores, etnias y lenguas se podía convertir al islam y convertirse en «buenos musulmanes». Es esta opción a la conversión que ha hecho del islam la mayor religión abrahámica del mundo; irónicamente, es la ausencia misma de esta misión de conversión lo que sorprende de la nueva jihad.

La nueva jihad no es tan sólo apocalíptica, es nihilista. La afirmación de un portavoz talibán de que su gente aprecia la muerte tanto como los americanos

5. Roxanne EubEN, «Killing (for)Politics: Jihad, Martyrdom, and Political Action», conferencia dada en el Political Theory Colloquium, Yale University, 16 de octubre de 2001. En el Political Theory de febrero de 2002. 
la vida, es una expresión de sensacional nihilismo. Es singular la erotización de la muerte, como lo evidencian, por un lado, los frecuentemente escuchados vulgarismos sobre las huris, las vírgenes de ojos negros que recibirán a los guerreros en el más allá y, por otro y más importante, la destrucción del propio cuerpo en un acto de suprema violencia que lo desmiembra y desmenuza. Los seres humanos han muerto a lo largo de siglos por causas en las que creían, por salvar a sus seres queridos, y cosas por el estilo. Pero la aparición de los «terroristas suicidas» entre los grupos islamistas a escala masiva es sorprendente. Como han señalado muchos eruditos coránicos, no hay justificación teológica para este hecho: una cosa es morir en la guerra y otra hacer de la destrucción del propio cuerpo, junto con los de otros, el arma suprema. Con objeto de abochornar a estas oleadas de terrorismo suicida, las autoridades israelíes recurrieron a una práctica atávica: hicieron saber públicamente que enterrarían a los restos de terroristas suicidas en mortajas de piel de cerdo (un animal que es considerado haram - 'tabú'-, tanto por los judíos como por los musulmanes), para evitar que subiesen al cielo según la fe islámica. Es difícil saber, desde luego, si hombres de la sofisticación y la mundanidad de Muhammad Atta y otros, que han vivido en las capitales de Europa y Occidente y han ido a sus universidades, y también a los bares, cines y burdeles, creen en el más allá. Personalmente lo dudo. No tan sólo queda claro que la versión muy estricta del islam — wahhabisme - que Osama bin Laden sigue no es seguida por todo el mundo, ni siquiera dentro de su grupo, sino también que la Hermandad Egipcia (Brotherhood), que era la organización que dio lugar a muchas filosofías islamistas de los años cincuenta, tenía su propia versión de las cosas, como también los miembros de la red de terror argelino. Estas redes de jóvenes militantes que trotan por el mundo, de Bosnia a Afganistán, de París a Indonesia, para volver a Bagdad, Hamburgo o Nueva York, son como mercenarios islámicos, a la búsqueda, no de las riquezas, sino de un encuentro difícil y decisivo con la muerte. En este sentido, de entre todas las religiones del mundo, se asemejan más a sectas milenaristas que a los ejércitos de los Umayyad, el Abassids o los Otomanos. Aunque utilizan gobiernos musulmanes amigos y su hospitalidad para conseguir sus propósitos, estos grupos representan una clara amenaza para cualquier forma de autoridad establecida, lo cual puede haber sido una razón por la que los saudíes denegaron la ciudadanía a Osama bin Laden y lo convirtieron en un fugitivo internacional.

Igual que en el siglo pasado, enfrentadas a una nueva forma de totalitarismo, las democracias se enfrentan a retos únicos. La presencia de un enemigo, que no es ni un adversario militar ni un agente que represente a un estado conocido, crea confusión sobre si la policía, las otras agencias policiales o el ejército tendrían que ponerse al frente de la investigación y la lucha; las líneas entre actos criminales y actos de guerra se desdibujan. El concepto de un «enemigo interno", que está siendo ahora promovido contra "grupos sospechosos", con vigilancia, intervención de teléfonos y controles de inmigración más estrictos, no es un concepto con el que las democracias puedan vivir. La categoría del terrorista como «enemigo interno" que vive entre nosotros, aunque no es uno 
de los nuestros, daña la comunidad democrática cuando muestra que el imperio de la ley no es inclusivo y que la violencia está al quite en los extremos de la normalidad cotidiana. Nuestra opinión sobre los extranjeros, los refugiados y los asilados se ve marcada por la imagen de los otros como enemigos potenciales; "el otro» deviene el delincuente. Es posible que nos encontremos en un punto de la historia en que el sistema centrado en el estado esté decayendo: el terrorismo global y la formación de una economía global y la sociedad civil son parte del mismo vórtice. Sin embargo, nuestras leyes e instituciones, prácticas y alianzas, están gobernadas por términos centrados en el estado que presuponen la unidad de territorialidad, el monopolio del uso de medios de violencia y la consecución de legitimación a través de instituciones representativas. Naturalmente, es del todo irónico que el presidente Bush, que defendía una nueva versión de unilateralismo y el aislacionismo americano y que censuraba la "construcción de naciones», dé ahora apoyo a las acciones multilaterales con aliados como Pakistán, Arabia Saudí y Siria, la legitimación democrática de las cuales es altamente cuestionable, y también reconstruyendo un gobierno posttalibán en Afganistán. ¿Podemos encontrar respuestas a este nuevo reto que rompa los círculos viciosos de violencia, incomprensión y represión en casa y de guerra en el exterior?

Aunque los ataques se han dirigido hasta ahora contra los EEUU, y aunque los EEUU están justificados por la ley internacional cuando invocan el derecho a la autodefensa para justificar la guerra actual ${ }^{6}$, los Estados Unidos y sus aliados de la OTAN han recurrido a la cláusula de seguridad colectiva y al artículo 5 de la OTAN, el cual garantiza la seguridad de cada miembro de la Alianza. Yo apoyo esta línea de acción, y apoyaría también a un llamamiento del presidente de las Naciones Unidas, Kofi Annan, para declarar el terrorismo un "crimen contra la humanidad» y juzgar a los terroristas, cuando sean capturados, ante un tribunal internacional. Aún más, la Asamblea General de las Naciones Unidas tendría que condenar el régimen talibán por cometer crímenes contra la humanidad, no solamente por dar refugio a Osama bin Laden y a sus hombres, sino por la manera como han pisado los derechos humanos de sus propias mujeres. No hay ninguna razón para que los derechos humanos de las mujeres a trabajar, a recibir una educación, a andar por la calle, a vestirse como les plazca, etc., tengan que ser considerados menos sagrados y menos necesarios que la defensa de los derechos de las minorías étnicas. En respuesta a los acontecimientos del once de septiembre y a futuras amenazas, se habrían de invocar a las respuestas multilaterales que disfrutan de legitimidad transcultural y reflejan algunas de las nuevas formas de derecho internacional - como, por ejemplo, crímenes contra la humanidad o genocidio, definidos por el Estatuto de Roma del Tribunal Penal Internacional. Desgraciadamente, las acciones actuales de la Administración Bush tienden a ir en sentido contrario:

6. Para una aclaración de la situación actual desde el punto de vista del derecho internacional, ver Richard FALK, "A Just Response», The Nation, 8 de octubre de 2001. 
los soldados talibanes y de Al Qaeda han sido declarados «combatientes no militares» y serán juzgados por tribunales militares, en el espacio extraterritorial de la bahía de Guantánamo, la cual no está sujeta a la protección constitucional de los Estados Unidos. Tal y como hizo con la renuncia a los acuerdos de Kyoto y Salt II, en torno a este tema la Administración Bush predica el internacionalismo pero practica el unilateralismo.

Naturalmente -y los ciudadanos de las democracias occidentales no pueden decirlo más claro- es necesaria una revisión radical de la política de los Estados Unidos y la OTAN con respecto al mundo árabe y al centro y sur de Asia. Los Estados Unidos y sus aliados tienen que dejar de apoyar a las dictaduras militares y a los conservadores religiosos de aquellas zonas tan sólo para asegurarse el suministro de petróleo. Se tiene que apoyar a los movimientos democráticos dentro de las reencontradas sociedades civiles de países como, por ejemplo, Egipto, Turquía y Jordania, y también el nuevo Irán. Se tiene que reunir la Asamblea General de las Naciones Unidas para tratar de los derechos de las naciones, las etnicidades y las otras minorías sin estado en esta región, como los kurdos de Turquía, Irak e Irán; los chiitas de Irak, y los bahaís y azerís de Irán. Esfuerzos parecidos al Plan Marshall en la Europa de posguerra o la Fundación Soros en la Europa del Este se tienen que desarrollar y promover para regiones enteras. Pero, aunque se asuman todas estas cosas, creo que empieza a hacerse evidente una aún más desalentadora lucha cultural y enfermedad de la civilización.

\section{II}

Como muchos ya han indicado (incluso la exministra del Pakistán Benazir Bhutto), los acontecimientos del once de septiembre parecían, en un primer momento, ofrecer una confirmación tardía de la famosa tesis de Samuel Huntington sobre el choque de civilizaciones. Huntington escribió:

Mi hipótesis es que la fuente fundamental de conflictos en este mundo no será principalmente ideológica o principalmente económica. Las grandes divisiones entre la humanidad y la fuente dominante de conflicto serán culturales. Los estados nacionales serán los actores más poderosos de los asuntos internacionales, pero los principales conflictos de la política global tendrán lugar entre naciones y grupos de diferentes civilizaciones. Las lineas de falla que hay entre las civilizaciones serán las lineas de batalla del futuro ${ }^{7}$.

Procediendo de una comprensión holística de las culturas y las civilizaciones - términos que a veces combinaba y que otras distinguía-, Huntington fue incapaz de diferenciar una "civilización» de otra, con el resultado de que, aparte «de occidente y el resto», no podía especificar cuántas civilizaciones

7. Samuel Huntington, The Clash of Civilizations and the Remaking of World Order, Nueva York, Simon and Shuster, 1996, p. 2. 
había ni como se diferenciaban ${ }^{8}$. Edward Said señaló que Huntington convertía a las civilizaciones y a las identidades en:

[...] entidades cerradas y selladas que han sido purgadas a partir de las miríadas de corrientes y contracorrientes que estimulan a la vida humana, y a lo largo de los siglos han hecho posible que esta historia contenga no sólo guerras de religión y conquista imperial, sino que también sea una historia de intercambio, encrucijada y contribución?

Es precisamente a esta historia de encrucijada —intercambio y también confrontación - entre las culturas islámicas y occidentales, a la que tenemos que prestar más atención. Uno de los pensadores principales del movimiento islamista ${ }^{10}$, Sayyid Qutb, un egipcio que estudió filosofía en Francia y visitó brevemente los Estados Unidos, desarrolló una crítica civilizacional de occidente por su corrupción, frialdad, crueldad e individualismo. Su crítica recuerda a temas de los trabajos de Nietzsche a Heidegger, de Adorno a Horkheimer y de los comunitaristas contemporáneos ${ }^{11}$. Al describir la situación actual de occidente como una situación de jahiliyya, falta de conocimiento e ignorancia, los islamistas defienden un regreso a la ley alcoránica — la shari 'a — y a los preceptos islámicos para combatir las corrupciones de la forma de vida occidental. Para combatir la situación de jahiliyya, es necesario rebelarse y establecer una contracomunidad (jama'a) y propagarla mediante la jihad ${ }^{12}$. A menudo, la lucha de los islamistas contra la jahiliyya toma la forma de lucha contra las autoridades establecidas en sus propios países y sus políticas occidentalizadas y corruptas.

Este choque dentro de los países islámicos entre las fuerzas religiosas islamistas y las modernizadoras, como por ejemplo Kemal Ataturk en Turquía; Habib Burgiba en Túnez; Gemal Abdel Nasser, Anwar Sadat y Hosni Mubarak en Egipto; el destituido Reza Shah Pahlavi en Irán, e incluso Saddam Hussein en Irak, es largo, profundo y potente. Los modernizadores de estos países normalmente vienen de un trasfondo militar en lugar de civil, y al transformar una de las pocas instituciones intactas del viejo régimen —es decir, la burocracia militar - en un instrumento de poder y hegemonía política, han consolidado su autoridad, a menudo con un apoyo civil y unas instituciones democráticas muy limitadas. En todo el mundo islámico árabe, este paradigma de

8. Ver mi próximo The Claims of Culture: Equality and Diversity, Princeton, Princeton University Press, 2002. En la introducción, trato de las dificultades conceptuales y explicativas de las tesis de Huntington.

9. Edward Said sobre Samuel Huntington, en Al-Ahram Weekly On-line, <http://www.ahram. org.eg/weekly/standard/aaw.gif>, núm. 555, 11-17 de octubre de 2001.

10. Roxanne Euben observa que «Islamismo es una manera ligeramente menos controvertida de referirse al fundamentalismo islámico» («Killing (for) Politics»).

11. Ver el excelente libro de Roxanne Euben, Enemy in the Mirror: Islamist Fundamentalism and the Limits of Modern Rationalism, Princeton, Princeton University Press, 1999.

12. Euben, «Killing (for) Politics», núm. 8. 
modernización militar, en el que Siria e Irak participaron por la vía de los regímenes Ba’ath durante los años setenta, ha perdido terreno. La derrota de los ejércitos egipcios a manos de Israel durante la Guerra de los Seis Días, y la ocupación israelí de la Franja de Gaza son un recordatorio a la élite militar de estos países, no tanto de la lucha de los palestinos, a quienes ellos han masacrado y oprimido cuando les convenía (recordemos el Septiembre Negro en Jordania en 1970, donde los palestinos fueron asesinados a millares, o las persecuciones de palestinos por parte de los saudíes debido a su apoyo a Saddam Hussein durante la Guerra del Golfo), como del fracaso de sus proyectos truncados. Israel es una espina clavada en estos regímenes, su sola presencia les recuerda su fracaso al no modernizarse en términos militares, tecnológicos y económicos.

El avivamiento de los movimientos islamistas se comprende mejor a partir del fracaso de la mayoría de estas sociedades para conseguir combinar una economía próspera con una democracia política y una identidad musulmana ${ }^{13}$. El islamismo aparece como un proyecto de civilización plausible, no solamente contra occidente, sino también contra el fracaso de las élites ocicidentalizadoras, que sólo han conseguido importar a sus sociedades una modernidad truncada. Algunas de estas élites modernizadoras se habían considerado «socialistas» en cierto modo. Los regímenes Ba’ath de Siria e Irak, e incluso el tipo de panarabismo concebido por Nasser a principios de los años sesenta, abogaban por unas fuertes medidas de redistribución económica, un fortalecimiento de los sectores públicos (en servicios de propiedad estatal, por ejemplo), y practicaban aquello que se podría denominar «modernización estatista» desde arriba. La desaparición de la Unión Soviética ha dejado estos estados sin protectores. ¿Tenemos que recordar que la movilización de los mujahedeen islamistas de Afganistán empezó contra la invasión soviética del país en 1979 —una invasión en la que los soviéticos se implicaron para apoyar a sus propios partidarios, los izquierdistas fedayyeen?

El colapso de los socialismos realmente existentes y el fracaso antes mencionado de la modernización promovida por el estado, han creado un enorme vacío en la vida ideológica de estas sociedades. Y hacia este vacío se han dirigido los fundamentalistas islámicos. Osama bin Laden es el miembro más espectacular de una larga cadena de críticos dentro del mundo islámico, los que, la mayoría de veces, han orientado sus luchas locales contra sus propios regímenes corruptos y autoritarios hacia fuera, hacia el enemigo externo (Nasser prohibió la Hermandad Musulmana Islamista [Islamist Muslim Brotherhood] y colgó a algunos de sus líderes).

13. Ver Sayres S. Rudy para un análisis teórico social en profundidad de algunos de estos temas, "Subjetividad, evaluación política y trayectorias islamicas», en: Birgit SCHAEBLER y Leif STENBERG (eds.), Globalization and the Muslim World, Albany, SUNY Press, 2002. 


\section{III}

Quiero terminar con la pregunta de Max Weber: ¿qué direcciones toma hoy el rechazo religioso en el mundo y por qué? ${ }^{14}$. Hay un conflicto fundamental entre la modernidad secular y capitalista, impulsada por el beneficio, el egoísmo y el individualismo, y las visiones éticas de las religiones del mundo. Las visiones religiosas del mundo predican varias formas de abstinencia, renuncia a las riquezas, búsqueda de la virtud en el camino de Dios, ejercicio de solidaridad entre los miembros de la fe y disciplina en la vida diaria para hacer la obra de Dios. ¿Qué es, preguntó Weber, lo que permite a algunas interpretaciones religiosas del mundo hacer las paces con el nuevo mundo de la modernidad? Para Weber, la ética protestante exhibió su "afinidad electiva» hacia el capitalismo, al transformar la búsqueda abstinente y metódica de la vocación de uno mismo en el servicio a Dios en la búsqueda metódica, previsible y disciplinada del trabajo y el beneficio en este mundo. Este proceso tardó bastantes siglos y no todos los cristianos modernos al principio aceptaban la lógica: los movimientos milenaristas que desechaban el control capitalista de la vida diaria a favor del trabajo disciplinado y el beneficio, acompañaron al ascenso de la modernidad occidental.

La transformación protestante - y más concretamente calvinista - de la salvación religiosa en una vocación terrenal de trabajo duro al servicio de un dios imprevisible, es uno de los muchos caminos que puede tomar la acomodación religiosa en el mundo. También es posible dividir las esferas religiosa y mundana de tal manera que una se retira totalmente del compromiso con el mundo; la abnegación religiosa del mundo sigue siendo una opción. Una tercera opción - aparte del compromiso o la retirada - es compartimentalizar separando las esferas de la vida que están bajo el dictado ético de la religión, de aquéllas como las esferas públicas de la economía, en las cuales es posible más flexibilidad y transigencia. Por todo el mundo islámico se practicaba una separación así de estricta entre la observancia religiosa (en el ámbito de la vida familiar y las prácticas diarias de la oración, la limpieza, la comida y la sexualidad) y la esfera de la economía en el bazaar ('el mercado'). Esta separación entre hogar y mercado era posible por la práctica de la tolerancia islámica hacia las otras religiones abrahámicas, como el judaísmo y el cristianismo. Los otomanos adoptaron este modelo de las «esferas separadas», y permitían que una amplia serie de grupos étnicos y pueblos a quienes ellos dominaban se gobernaran en sus propios asuntos comunales de acuerdo con sus tradiciones y costumbres religiosas (el denominado sistema millet). La modernización global está destruyendo el frágil equilibrio entre estas esferas separadas: esto puede explicar, también, la obsesiva preocupación por controlar la sexualidad femenina que muestran todos los grupos islamistas.

La modernización técnica, que conlleva dispositivos de la modernidad, como por ejemplo ordenadores, vídeos, DVD, teléfonos móviles o cadenas

14. Max Weber, «Religious Rejections of the World and Their Directions», Economy and Society, vol. 1. 
parabólicas, no es una amenaza para los islamistas ${ }^{15}$. De hecho, hay una explotación despiadada de estos nuevos medios para hacer llegar su mensaje a los creyentes. Tampoco el capitalismo financiero es problemático desde una perspectiva islámica. Por todo el mundo musulmán hay intentos de reconciliar la sharia con las instituciones financieras modernas. Ya sea con el método hawale de transferencia de dinero, el cual ignora los bancos modernos y confía en los contactos personales entre los prestamistas de dinero; o con la obligación del rico de compartir un 5\% de su riqueza con los pobres, tal y como lo dicta el Corán (una práctica que está en parte detrás de la financiación de las Madrassas o instituciones de enseñanza religiosa para huérfanos de guerra en Afganistán, por parte de individuos ricos de todo el mundo islámico), están teniendo lugar innovaciones institucionales para hacer el islam compatible con el capitalismo global. La amenaza al modelo de las esferas separadas es principalmente una amenaza a la vida familiar y personal.

El capitalismo global trae las imágenes de libertad sexual y decadencia, emancipación de la mujer e igualdad entre los sexos a los hogares de comunidades musulmanas patriarcales y autoritarias. Hollywood lo identifican con América; no así la Constitución, el Tribunal Supremo o el legado del puritanismo y los consejos abiertos. Estas imágenes de libertad y decadencia sexual, de destrucción física y violencia que circulan rápidamente, se venden muy bien a nivel mundial, porque el mensaje es contundente y se puede desvincular del matiz cultural local.

En un mundo global, no sólo son las imágenes las que viajan; los individuos de todo el mundo islámico forman parte de una gran diáspora hacia occidente. Existen importantes comunidades musulmanas en cada gran capital europea y norteamericana. Estas comunidades de emigrantes intentan practicar el modelo de esferas separadas en sus nuevos hogares. Pero los hijos de los emigrantes musulmanes están atrapados entre los dos mundos: bien sea por las instituciones educativas o por la influencia de la cultura de masas, están entre las estructuras familiares autoritarias y patriarcales de las que ellos salen y el nuevo mundo de libertad en el que entran. Hay una continua renegociación de códigos morales y orientaciones de valores que chocan en las mentes de esta generación más joven, particularmente respecto a las mujeres. Si queremos comprender por qué tantos jóvenes musulmanes educados y relativamente bien situados, que habían vivido en Hamburgo y París, participaron en las

15. A finales de los años ochenta, cuando visité Alemania por primera vez como miembro de la junta de Humboldt en Munich, me chocó mucho la venta de casetes y cintas de vídeo de cantos del Corán en grandes centros comerciales. Grabadas por conocidos Muezzins (cantores), estas cintas permitían a los fieles utilizar la tecnología de la sociedad que les rodeaba, a la vez que continuaban fieles a sí mismos. La ironía es que los cantos del Corán, al igual que las lecturas del Antiguo Testamento, y a diferencia de la lectura de la Biblia, se supone que tienen que ser actos comunales y colectivos de canto, cuentos y recordatorios. Los medios de la tecnología occidental amenazan este tejido comunal. El resultado puede ser una "religión a la carta», como es denominado este fenómeno también por muchos musulmanes. 
acciones del once de septiembre, hemos de entender la psicología de los inmigrantes musulmanes en su encuentro con las democracias seculares liberales de occidente. Dado el fracaso de sus propias versiones de la modernidad, como por ejemplo el naserismo y el movimiento $\mathrm{Ba}$ 'ath, dado el profundo asalto a su identidad de musulmanes por parte de la industria global de entretenimiento, y dada la profunda discriminación y desprecio que ellos experimentan en sus sociedades huéspedes como nuevos inmigrantes con una moral y una forma de vida "al revés», muchos jóvenes musulmanes recurren al islamismo y al fundamentalismo. Comentando el affaire foulard (el asunto del pañuelo de cabeza) en Francia, donde algunas estudiantes musulmanas empezaron a llevar los pañuelos tradicionales, no tanto como signo de sumisión al patriarcado religioso, sino como signo de diferencia y desafío contra las tradiciones republicanas homogeneizantes francesas, los sociólogos franceses Gaspard y Khosrokhavar captan este juego de negociaciones simbólicas complejas de la siguiente manera:

[El pañuelo de la cabeza] refleja a los ojos de los padres y los abuelos las ilusiones de continuidad, pero es un factor de discontinuidad; hace posible la transición a la alteridad (modernidad), bajo el pretexto de identidad (tradición); crea el sentimiento de identidad con la sociedad de origen, mientras que su significado está inscrito dentro de la dinámica de relaciones de la sociedad receptora [...] es el vehículo del pasaje a la modernidad dentro de una promiscuidad que confunde las distinciones tradicionales, de un acceso a la esfera pública que era prohibida a las mujeres tradicionales como espacio de acción y la constitución de autonomía individual $[\ldots]^{16}$.

Podemos intervenir en este proceso de negociaciones culturales complejas como compañeros de diálogo en una civilización global sólo en la medida en que hacemos un esfuerzo por comprender las luchas de otros, los idiomas y los términos de los cuales pueden no sernos familiares, pero que, por esto mismo, no son tan diferentes de luchas parecidas en otros momentos de nuestras culturas; mediante actos de fuerte generosidad hermenéutica, podemos ampliar nuestra imaginación moral para ver el mundo con los ojos de los otros $^{17}$. Aunque creo que, a estas alturas del conflicto, el uso de la fuerza contra la red de Osama bin Laden es inevitable y justificada, la tarea política real que tenemos por delante es entrar en un diálogo con millones de musulmanes de todo el mundo — más allá de la revancha y sin expectativas apocalípticas. Las democracias no pueden luchar en guerras santas. La razón, la compasión, el respeto a la dignidad de la vida humana, la búsqueda de la justicia y el deseo de reconciliación son las virtudes democráticas que ahora se oponen a los actos de odio apocalíptico y revancha.

16. Françoise Gaspard y Farhad Khosrokhavar, Le Foulard de la Republique, París, Découverte, 1995, p. 44-45.

17. Trato de la ética de la comunicación y el multiculturalismo en The Claims of Culture, cap. 5. 